\title{
A produção acadêmica sobre conteúdos de ensino na educação física escolar
}

\author{
Juliana Martins Cassani Matos* \\ Omar Schneider ${ }^{* *}$ \\ André da Silva Mello ${ }^{* * *}$ \\ Amarílio Ferreira Neto ${ }^{* * * *}$ \\ Wagner dos Santos ${ }^{* * * * *}$
}

\begin{abstract}
Resumo: Objetiva analisar as produções acadêmicas que tratam sobre os conteúdos de ensino da Educação Física escolar. Utiliza como fonte os periódicos científicos da área no período de 1981 a 2010. Foram mapeados 146 artigos distribuídos em 14 periódicos. Os dados foram classificados/ analisados por meio de indicadores bibliométricos, como distribuição anual, distribuição por revista e por conteúdo, relação autoral, formação profissional, origem demográfica e institucional, assim como vínculo a grupos de pesquisa. Embora haja, na produção acadêmica, um discurso que questione o Esporte como prática central da Educação Física escolar, este continua concentrando maior volume de trabalhos.
\end{abstract}

Palavras-chave: Educação física. Produção científica. Conteúdos de ensino. Periódico.

\footnotetext{
"Mestranda em Educação Física pela Universidade Federal do Espírito Santo. Instituto de Pesquisa em Educação e Educação Física (Proteoria), Vitória, ES, Brasil. E-mail: julianacassani@gmail.com

"Programa de Pós-Graduação em Educação Física. Universidade Federal do Espírito Santo. Pesquisador do Instituto de Pesquisa em Educação e Educação Física (PROTEORIA). Vitória, ES, Brasil. E-mail: omarvix@gmail.com

"'Programa de Pós-Graduação em Educação Física. Universidade Federal do Espírito Santo. Pesquisador do Instituto de Pesquisa em Educação e Educação Física (PROTEORIA). Vitória, ES, Brasil. E-mail: andremellovix@gmail.com

-...Programa de Pós-Graduação em Educação Física. Universidade Federal do Espírito Santo. Pesquisador do Instituto de Pesquisa em Educação e Educação Física (PROTEORIA). Vitória, ES, Brasil.E-mail: amarilio@proteoria.org

-..."Programa de Pós-Graduação em Educação Física. Universidade Federal do Espírito Santo. Pesquisador do Instituto de Pesquisa em Educação e Educação Física (PROTEORIA). Vitória, ES, Brasil. E-mail: wagnercefd@gmail.com
} 


\section{ArtigosOriginais}

Juliana Matos et al.

\section{INTRODUÇÃo}

Estudos do tipo "estado do conhecimento", que fazem uma análise da produção acadêmica em uma determinada área e em um período estabelecido, têm sido férteis ao revelar objetos, recortes, temáticas, teorias e metodologias priorizados pelos pesquisadores, fornecendo importantes elementos para aperfeiçoar e indicar a necessidade de pesquisas em um determinado campo do saber (ANDRÉ, 2009). Esses mapeamentos são fundamentais para identificar redundâncias, omissões, modismos, fragilidades que, se adequadamente considerados, contribuem para o reconhecimento do status científico da área e indicam caminhos para seu fortalecimento na comunidade acadêmica.

No campo da Educação Física, pouca visibilidade é dada às pesquisas que nos permitem traçar um mapeamento e analisar a produção científica, indicando limites e avanços obtidos, assim como evidenciando as lacunas apresentadas por essa produção (CARNEIRO, 2011; FERREIRA NETO et al., 2003; SCHNEIDER, 2010; SOUZA; MARCHI JÚNIOR, 2011; BRACHT et al., 2011; BRACHT et al., 2012). Diante desse panorama, objetivamos analisar as produções acadêmicas que tratam sobre conteúdos de ensino da Educação Física escolar, referentes ao período de 1981 a 2010 .

A necessidade de compreendermos as produções teóricas de um período que paulatinamente afirmou a perda de identidade da Educação Física no espaço escolar, visto que seu conteúdo central, o esporte institucionalizado, fora incisivamente questionado, fez-nos periodizar o estudo entre o início dos anos de 1980 e o final do ano de 2010 e utilizar como fonte os periódicos da área, uma vez que são fontes privilegiadas para se entender os atores/autores e as propostas da Educação Física.

Mas o que entendemos como conteúdos de ensino? Seriam valores e atitudes, conhecimentos e habilidades? Manifestações da cultura corporal de movimento, das experiências sociocorporais ou mesmo o patrimônio cultural corporal? Com base nos estudos de 
Certeau (2002), podemos ter outro entendimento acerca dos conteúdos de ensino da Educação Física escolar, quando comparado com o que é usualmente apresentado pela área.

Compreendemos o conteúdo como algo menos fechado e mais fluído sobre a dinâmica cultural, o que permite, sem polarizar/ dicotomizar o intelectual do corporal e o social do cultural, resgatar um termo muito utilizado na constituição histórica da Educação Física e que, aos poucos, foi perdendo terreno para terminologias autodenominadas críticas e reflexivas. Estamos falando da noção de práticas, expressão que causa desconfiança na área, pois foi associada a atividades eminentemente práticas, consideradas sem consequências para a formação reflexiva do estudante na Educação Básica.

Para Certeau (2002), as formalidades das práticas são reveladoras das formas de aprendizagem/apropriação e uso dos conhecimentos socializados por meio de diferentes instituições e dispositivos de circulação. O autor propõe uma morfologia das práticas que somente é compreendida por meio de uma dialética que leve em consideração a lógica da ação. Dessa maneira, para projetarmos os conteúdos da Educação Física em termos de prática é preciso entendê-la como uma atividade que se realiza por meio de ações sobre uma matéria, no caso, uma matéria selecionada dos bens culturais produzidos historicamente.

Os bens culturais dos quais nos servimos não são outros senão a Dança, Esportes, Ginásticas, Lutas, Capoeira, Jogos, Brincadeiras etc. Contudo, o tratamento pedagógico dispensado a essas atividades não se restringe ao fazer de maneira crítica ou reflexiva, uma vez que a prática, em Certeau (2002), se materializa por meio de um processo antropofágico de consumo, que não pode ser confundido com um modelo conspícuo, já que, em muitos momentos, esse processo não é claramente visível.

Desse modo, o que importa é o que o praticante consome, mas também o que ele faz com o que foi consumido. Portanto, é preciso compreender que produto é esse que foi materializado da prática de 
consumo de bens culturais, levando em consideração que, conforme Hunt (1995, p. 9), "As relações econômicas e sociais não são anteriores às culturais, nem as determinam; elas próprias são campos de prática cultural e produção cultural [...], [ou seja, não existe] uma dimensão extracultural da experiência".

Como já anunciado por Schneider e Bueno (2005), os conhecimentos com os quais a Educação Física lida no ensino são atividades constantemente submetidas a minivariações de situações de aplicação, por isso em muitos momentos percebidas como menos dignas no universo da cultura escolar.

Segundo Charlot (2009), o objetivo fundamental de uma educação que se pretende física, que visa ao corpo, é o próprio corpo, ou seja, a apropriação de regras e reflexividade vale quando elas oferecem suporte a práticas incorporadas no corpo. O conteúdo, dessa maneira, não pode ser definido pelo que se encontra exterior ao praticante, ele deve ser considerado tendo em vista o modo como esses praticantes se relacionam com o saber (CHARLOT, 2000), dando sentidos e significados às suas experiências.

A fim de evidenciarmos como os conteúdos de ensino têm se feito presentes nas produções acadêmicas da Educação Física, assumimos, no referencial teórico-metodológico, as orientações para pesquisas que tratam o periódico como fonte, assim como as relações de força que se estabelecem no interior da produção científica (GINZBURG, 2002). Indicamos ainda o caminho percorrido para seleção dos artigos e, posteriormente, analisamos o mapeamento realizado por meio de indicadores bibliométricos (MUGNAINI; CARVALHO; CAMPANATTI-OSTIZ, 2006).

\section{REFERENCIAL TEÓRICO-METODOLÓGICO}

Os estudos do tipo "estado do conhecimento" descrevem a distribuição da produção científica sobre um objeto, por meio de aproximações estabelecidas entre elementos contextuais e um conjunto de outras variáveis, como data de publicação, temas e 
periódicos (MOROSINI et al., 2002). O periódico, nesse caso, constitui-se como fonte privilegiada, a partir das quais analisamos as "[...] predominâncias ou recorrências temáticas e informações sobre produtores [...]" (CATANI; SOUSA, 1999, p. 11). Schneider (2010, p. 24) compreende que os periódicos podem evidenciar lacunas que reconstituam

[...] um passado aparentemente soterrado por várias camadas de história, um tempo contado e recontado, sistematizado em narrativas que em grande parte utilizam como referência as determinações econômicas, sociais e ideológicas, o que faz vir à tona, muitas vezes, apenas o Estado e sua política, e não as práticas e os dispositivos produzidos por agentes que habitam essa mesma realidade.

O impresso não deve ser entendido apenas como uma fonte de informações, de ideias, de imagens, mas, acima de tudo, como destaca Davis (1990, p. 159), como um mensageiro de relações, o qual possui como "[...] característica mais marcante [...] [o] papel de formador de opinião". Mais do que veicular informações sobre fatos ocorridos, a imprensa ajuda a dar forma ao que por ela é registrado (DARNTON, 1996). Assim, configura-se como um importante dispositivo de ideias ou prescrições pedagógicas, em que são reveladas as temáticas norteadoras da área (SCHNEIDER, 2010).

Estabelecemos, dessa maneira, uma análise sobre a produção acadêmica que discute conteúdos de ensino, por meio de indicadores bibliométricos, como distribuição anual, por revista e por conteúdo, relação autoral, formação profissional, origem demográfica e institucional, assim como vínculo a grupos de pesquisa ${ }^{1}$.

Ao lidarmos com as fontes, damos visibilidade às estratégias de conservação e táticas de subversão (CERTEAU, 2002) que coexistem em um campo científico, observando os entrecruzamentos das produções acadêmicas e sua articulação com os grupos de pesquisadores e seus vínculos institucionais. De acordo com Certeau

${ }^{1}$ Tomamos como referência os estudos desenvolvidos por Santos (2011) e Carneiro (2011), tendo em vista a organização dos dados e aproximações realizadas entre as informações existentes no corpo dos artigos e as cadastradas na Plataforma Lattes. 
(2002), as estratégias são manipulações das relações de força que sustentam e conquistam lugares de produção. Ao contrário das estratégias, as táticas de subversão são ações geradas pela ausência de lugares próprios, como um último recurso daqueles que, com mobilidade, se submetem aos que detêm o poder, a fim de que suas ações influenciem no espaço (CERTEAU, 2002).

A constituição do corpus documental da pesquisa foi delimitada por meio de leitura prévia do título dos artigos, dos resumos e, quando necessário, dos textos na íntegra. Estabelecemos como parâmetro de busca o termo conteúdos de ensino e, posteriormente, ampliamos para temas que nos remetessem aos próprios conteúdos, como Dança, Ginástica, Esportes, dentre outros. Utilizamos como fonte o Catálogo de periódicos de educação física e esporte (FERREIRA NETO et al., 2002) e as versões on_line dos impressos da área. Mapeamos previamente 523 artigos, presentes em 23 revistas.

Após análise detalhada, esse número foi reduzido para 146 trabalhos, distribuídos em 14 periódicos: Conexões, Corporis, Discorpo, Educativa, Kinesis, Motrivivência, Motriz, Movimento, Pensar a Prática, Perfil, Revista Brasileira de Ciências do Esporte (RBCE), Revista Brasileira de Ciência \& Movimento (RBCM), Revista da Educação Física/UEM (REF-UEM) e Revista Mineira de Educação Física (RMEF).

Eliminamos os trabalhos que não apresentaram em seu corpo as referências, os que se configuravam como resumos e os que foram publicados em Anais de Congresso. A exclusão dos Anais foi realizada por tratar-se de literatura com restrições quanto à sua acessibilidade, aquisição e controle específico, denominada "bibliografia cinzenta" (FUNARO; NORONHA, 2006). Suprimimos ainda os que não caracterizavam a temática em estudo como objetivo central. 


\section{DEBATE SOBRE CONTEÚDOS DE ENSINO: MAPEAMENTO DAS PRODU- ÇÕES}

Com base na leitura dos textos, analisamos as fontes mapeadas organizando-as em: distribuição anual, procedência autoral, formação profissional, relação entre procedência territorial, institucional e grupos de pesquisa.

3.1 DA DISTRIBUIÇÃO ANUAL DOS ARTIGOS: INDÍCIOS DE PRÁTICAS EDITORIAIS

A análise da distribuição anual dos 146 artigos indica como essa temática é recorrente na área. O período de 1981 a 2000 representa $29 \%$ das publicações (43 artigos), com maior produção nos anos de 1996 (10) e 2000 (9). Em contrapartida, 71\% dos trabalhos concentram-se entre 2001 a 2010 (103), com maior representatividade numérica em 2007 (15), 2008 (23) e 2009 (14), conforme Tabela 1:

Tabela 1 - Distribuição Anual por Periódico

\begin{tabular}{|c|c|c|c|c|c|c|c|c|c|c|c|c|c|c|c|c|c|c|c|c|c|c|c|}
\hline \multirow{2}{*}{ Periódico } & \multicolumn{22}{|c|}{ Ano } & \multirow{2}{*}{ Total } \\
\hline & 86 & 89 & 90 & 91 & 92 & 93 & 95 & 96 & 97 & 98 & 99 & 00 & 01 & 02 & 03 & 04 & 05 & 06 & 07 & 08 & 09 & 10 & \\
\hline Conexões & & & & & & & & & & & 1 & & & & & & & & & 2 & & & 3 \\
\hline Comporis & & & & & & & & 3 & & 2 & & & & & & & & & & & & & 5 \\
\hline Dis corpo & & & & & & & 1 & & & & & & & & & & & & & & & & 1 \\
\hline Educativa & & & & 1 & & & & & & & & & & & & & & & & & & & 1 \\
\hline Kine sis & & & & & & & & & & 1 & \begin{tabular}{|l|}
2 \\
\end{tabular} & & & & & & & & & & & & 3 \\
\hline Motrivivência & & 2 & & & & 1 & 1 & 4 & & & 3 & 1 & & & & & 1 & & 2 & 11 & 1 & & 27 \\
\hline Motriz & & & & & & & 1 & 2 & & 1 & & & & 1 & 1 & 1 & 3 & 2 & 4 & 2 & 4 & 7 & 29 \\
\hline Mov imento & & & & & & & & 1 & & & & 3 & 2 & 1 & 1 & 1 & & & 3 & 4 & 3 & & 19 \\
\hline Pens ar a Prática & & & & & & & & & & 1 & 1 & & 1 & & 3 & 3 & 1 & & & 2 & 1 & 1 & 14 \\
\hline Perfil & & & & & & & & & & & & 1 & & & & & & & & & & & 1 \\
\hline RBCE & 1 & & & & & & & & & & & 2 & 1 & 1 & 1 & & 1 & 2 & 3 & 1 & 2 & 1 & 16 \\
\hline RBCM & & & & 1 & & & & & & & & & 1 & & & 1 & & & 1 & & & & 4 \\
\hline REF-UEM & & & 1 & & 1 & & & & & & & 2 & 2 & 3 & & 1 & & 1 & 1 & 1 & 2 & 3 & 18 \\
\hline RMEF & & & & & & & & & 1 & & & & & & & 2 & & & 1 & & 1 & & 5 \\
\hline Total & 1 & 2 & 1 & 2 & 1 & 1 & 3 & 10 & 1 & 5 & 7 & 9 & 7 & 6 & 6 & 9 & 6 & 5 & 15 & 23 & 14 & 12 & 146 \\
\hline
\end{tabular}

Fonte: Autores

As publicações nas revistas de menor circulação, como Discorpo (1), Educativa (1), Perfil (1), Conexões (3), Kinesis (3), RBCM (4), Corporis (5) e RMEF (5), compreendem 16\% de toda a produção. A sua distribuição concentra-se nos anos 1996, 1998, 1999 e $2004^{2}$, representando $52 \%$ do que foi produzido por esses periódicos. Por outro lado, as produções presentes na Pensar a

${ }^{2}$ Considerando o mínimo de 3 artigos veiculados.

ovimento, Porto Alegre, v. 19, n. 02, p. 123-148, abr/jun de 2013. 
Prática (14), RBCE (16), REF-UEM (18), Movimento (19), Motrivivência (27) e Motriz (29) equivalem a 84\% do total de artigos analisados.

A distribuição anual das publicações nesses periódicos se configura de maneira expressiva de 2007 a 2010, representando 48\% de suas produções. Verificamos que poucos impressos põem em circulação artigos em um período maior, sem interrupção, como Motriz (2002 a 2010), Movimento (2000 a 2004), RBCE (2005 a 2010) e REF-UEM (2006 a 2010). Embora o volume publicado pelos periódicos, anualmente, oscile entre um a quatro artigos, são evidentes aqueles que veiculam um número maior de trabalhos, como a Motrivência, em 2008, e a Motriz, em 2010.

Tendo como prática a publicação de números temáticos, a Motrivivência assume em 2008 (n. 31) o tema "Conteúdos da Educação Física escolar", em que mapeamos 11 trabalhos. A política de agrupar o maior número de artigos sobre determinado assunto em um único volume contribui para que o perfil desse impresso seja reafirmado. Ao privilegiar discussões referentes à escola e às práticas pedagógicas, os editores garantem significativa homogeneidade aos discursos veiculados (FERREIRA NETO et al., 2003). Uma vez que o uso desse dispositivo não se apresenta de forma recorrente às demais revistas, a prática de não agrupar as pesquisas sob eixos temáticos contribui para a divulgação da produção científica dos diferentes campos do conhecimento (SANTOS, 2011). Sob essa perspectiva, a Motriz, tendo publicado sete artigos distribuídos em quatro números de 2010, destina-se à divulgação de pesquisas referentes à ciência da motricidade humana, abrangendo várias temáticas relacionadas com a Educação Física e áreas correlatas.

Quando comparamos o total de artigos postos em circulação pela Motriz (587) com o número de trabalhos publicados por ela sobre conteúdos (29), verificamos que essa produção corresponde a 4,94\% do total. Em contrapartida, dos 236 artigos veiculados na Motrivivência, $11,44 \%$ referem-se à temática em estudo, o que proporcionalmente a 
faz dedicar maior atenção ao tema. É preciso destacar que a Motriz possui periodicidade a cada três meses, a partir de 2007, enquanto a Motrivivência, a cada seis meses, a partir de 1999.

\subsection{DOS CONTEÚDOS ABORDADOS PELAS PRODUÇÕES ACADÊMICAS: EVIDENCIANDO LACUNAS}

Embora haja uma leitura sobre a necessidade da ampliação do debate sobre conteúdos de ensino, o Esporte continua sendo privilegiado pelos autores. Dos trabalhos analisados, 42 tratam sobre Esportes (29\%), 32 sobre Jogos e Brincadeiras (22\%), 25 Dança (17\%), 16 Ginástica (11\%), 4 Capoeira (3\%), 3 Lutas (2\%) e 24 abordam Vários Conteúdos $(16 \%)^{3}$. Intitulamos como Vários Conteúdos aqueles artigos que abordam dois ou mais conteúdos, assim como aqueles que tratam sobre a sua natureza e sistematização nos ciclos de aprendizagem.

Organizamos ainda os assuntos abordados pelos artigos, a fim de evidenciar as práticas discursivas que tratam de diferentes possibilidades de intervenção na Educação Física escolar. Os temas dança de rua (1), dança popular (2), dança folclórica (2), dança-improvisação (2), dança de salão (1), dança e inclusão (1) e dança-educação (2) foram agrupados na categoria Dança ${ }^{4}$. Categorizados como Esporte, encontramos futebol (6), handebol (4), atletismo (2), natação (1), tênis (1), esporte adaptado (1). Sobre Ginástica, identificamos ginástica geral (2), acrobática (1), circense (5), artística (1), e rítmica (2). Em Jogos e Brincadeiras, mapeamos brincadeiras açorianas (1), jogos populares (2), jogos eletrônicos (1), xadrez (2), jogos cooperativos (1) e brincadeiras folclóricas (1). Dos trabalhos sobre Lutas, encontramos judô (1) $)^{5}$.

\footnotetext{
${ }^{3}$ Considerando que a Capoeira é uma manifestação cultural em que jogo, luta e dança se relacionam diretamente (FALCÃO; SILVA;ACORDI, 2005), resolvemos mantê-la como categoria.

${ }^{4}$ Foram encontrados dois artigos que discutiam sobre diferentes temas relacionados com a Dança.

${ }^{5} \mathrm{O}$ mapeamento demonstrou ainda que um número significativo de trabalhos aborda os conteúdos de ensino sob diferentes perspectivas, sem caracterizá-los, como apresentado anteriormente. Desse modo, agrupamos os textos que assumem esse perfil em "questões gerais", dentre os quais Capoeira (4), Dança (16), Esporte (27), Ginástica (5), Jogos e Brincadeiras (24) e Lutas (2).
} 
A distribuição anual dos conteúdos indica que não houve produção no período de 1981 a 1985 . O Esporte foi o único conteúdo veiculado entre 1986 a 1991 e apresenta-se regularmente entre 1998 a 2010. Os artigos que trataram sobre Vários Conteúdos foram publicados a partir de 1992, Jogos e Brincadeiras 1995, Dança 1996 e Ginástica de 1998 em diante. Conforme Tabela 2, observamos que, enquanto a produção desses conteúdos se consolidava quantitativamente na década de 2001, o conteúdo Capoeira foi publicado apenas em 2000, 2001, 2004 e 2009, e as Lutas em 2007 e 2008.

Tabela 2 - Distribuição Anual dos Conteúdos

\begin{tabular}{|c|c|c|c|c|c|c|c|c|c|c|c|c|c|c|c|c|c|c|c|c|c|c|}
\hline \multirow{2}{*}{ Conteúdo } & \multicolumn{22}{|c|}{ Ano } \\
\hline & 86 & 89 & \begin{tabular}{|l|l}
90 \\
\end{tabular} & 91 & 92 & \begin{tabular}{|l|}
93 \\
\end{tabular} & 95 & 96 & 97 & 98 & 99 & 00 & 01 & 02 & \begin{tabular}{|l|}
03 \\
\end{tabular} & \begin{tabular}{|l|}
04 \\
\end{tabular} & \begin{tabular}{|l|}
05 \\
\end{tabular} & \begin{tabular}{|l|}
06 \\
\end{tabular} & \begin{tabular}{|l|}
07 \\
\end{tabular} & 08 & 09 & 10 \\
\hline Capoeira & & & & & & & & & & & & 1 & 1 & & & 1 & & & & & 1 & \\
\hline Dança & & & & & & & & 2 & 1 & 2 & 2 & & 1 & 2 & 3 & 1 & 1 & & 2 & 4 & 2 & 2 \\
\hline Esportes & 1 & 2 & 1 & 2 & & & 1 & 1 & & 2 & 4 & 4 & 3 & 1 & 2 & 1 & 1 & 1 & 2 & 6 & 3 & 4 \\
\hline Gin ás tica & & & & & & & & & & 1 & & 1 & & 1 & 1 & 2 & & & 4 & 3 & & 3 \\
\hline Jogos e Brincs. & & & & & & & 1 & 6 & & & & 3 & 1 & 1 & & 1 & 1 & 3 & 4 & 5 & 4 & 2 \\
\hline Lutas & & & & & & & & & & & & & & & & & & & 1 & 2 & & \\
\hline Vários & & & & & 1 & 1 & 1 & 1 & & & 1 & & 1 & 1 & & 3 & 3 & 1 & 2 & 3 & 4 & 1 \\
\hline Total & 1 & 2 & 1 & 2 & 1 & 1 & 3 & 10 & 1 & 5 & 7 & 9 & 7 & 6 & 6 & 9 & 6 & 5 & 15 & 23 & 14 & 12 \\
\hline
\end{tabular}

Fonte: Autores

A tabela evidencia uma concentração do Esporte em 2008, com seis trabalhos produzidos. Veiculado em cinco, dos sete periódicos postos em circulação, constituiu-se como o conteúdo de maior representatividade numérica naquele ano. Encontramos o maior índice de artigos sobre Jogos e Brincadeiras em 1996, e sobre Dança em 2008. Esses dados são decorrentes dos eixos temáticos publicados pela Motrivivência, que definiu, na edição n. 9, o tema Jogos e Brincadeiras, fazendo circular quatro trabalhos, e, no n. 31, a temática Conteúdos, com três artigos sobre Dança.

O trato pedagógico a determinados conteúdos, especialmente aqueles com menor visibilidade no campo acadêmico, parece ser, de fato, uma questão a ser debatida pela produção científica, haja vista poucos trabalhos que discutem a necessidade em transformar a Ginástica, a Capoeira e as Lutas em conteúdos de ensino escolar. 
Ao verificarmos o quantitativo de artigos por periódicos, observamos que as revistas com menor número de publicações priorizam temáticas relacionadas com conteúdos de maior circulação na produção científica, conforme Tabela 3:

Tabela 3 - Distribuição dos Conteúdos por Periódico

\begin{tabular}{c|c|c|c|c|c|c|c|c}
\hline \multirow{2}{*}{ Periódi co } & \multicolumn{7}{|c|}{ Conteúdo } & \multirow{2}{*}{ Total } \\
\cline { 2 - 10 } & Capoeira & Dança & Esportes & Ginástica & Jogos e Brinc. & Lut as & Vários & \\
\hline Conexõ es & & 1 & 1 & & 1 & & & $\mathbf{3}$ \\
\hline Corporis & & 3 & 1 & & 1 & & & $\mathbf{5}$ \\
\hline Dis corpo & & & & & 1 & & & $\mathbf{1}$ \\
\hline Edu cativa & & & 1 & & & & & $\mathbf{1}$ \\
\hline Kin esis & & & 1 & 1 & & & 1 & $\mathbf{3}$ \\
\hline Mo triv ivência & & 4 & 7 & 3 & 9 & 2 & 2 & $\mathbf{2 7}$ \\
\hline M otriz & 1 & 4 & 9 & 1 & 6 & & 8 & $\mathbf{2 9}$ \\
\hline Movimento & & 3 & 10 & 2 & 1 & 1 & 2 & $\mathbf{1 9}$ \\
\hline Pen sar a Prát ica & 1 & 4 & 4 & 3 & 1 & & 1 & $\mathbf{1 4}$ \\
\hline Perfil & & & & & 1 & & & $\mathbf{1}$ \\
\hline RBCE & & 2 & 3 & 1 & 7 & & 3 & $\mathbf{1 6}$ \\
\hline RBCM & & 1 & 1 & & 2 & & & $\mathbf{4}$ \\
\hline RMEF & & 2 & 1 & 1 & & & 1 & $\mathbf{5}$ \\
\hline REF-UEM & 2 & 1 & 3 & 4 & 2 & & 6 & $\mathbf{1 8}$ \\
\hline
\end{tabular}

Fonte: Autores

A concentração dos estudos sobre Esportes na Movimento (10) pode estar relacionada com a visibilidade que as discussões fomentadas pela seção Temas Polêmicos obtiveram no interior do impresso. Ao debater sobre assuntos como o "esporte de rendimento e o esporte na escola", a seção traz à tona a "[...] a identidade discursiva do impresso e a sua diferenciação no conjunto de periódicos científicos da área" (SCHNEIDER et al., 2009, p. 67). Os trabalhos referentes à Ginástica concentraram-se na REF-UEM, com quatro publicações, assim como aqueles que tratam sobre Vários Conteúdos na revista Motriz, com oito artigos veiculados.

\subsection{DA PROCEDÊNCIA AUTORAL: APROXIMAÇÕES COM A PÓS-GRADUAÇÃO}

Os artigos foram escritos por 215 autores, presentes tanto em trabalhos produzidos individualmente como coletivamente. Observamos que, nos anos de 1986, 1989 a 1991, 1993, 1995 e 1997, as produções foram publicadas por apenas um autor, conforme o Figura 1. 
Figura 1 - Procedência Autoral dos Artigos



Fonte: Autores

A concentração de estudos individuais refere-se a 1996 (9), representando $90 \%$ das publicações daquele ano. Esse tipo de autoria apresenta-se de modo significativo até o ano 2000, possivelmente pela ausência de políticas de fomento às pesquisas desenvolvidas em grupo. A partir de 2001, os artigos produzidos de modo coletivo se tornam mais presentes, mesmo que não se sobreponham aos escritos individualmente, como em 2003 e 2005.

Para Carneiro (2011), esse movimento pode ter sido impulsionado pelos critérios estabelecidos pela Coordenação de Aperfeiçoamento de Pessoal de Nível Superior (Capes) para avaliar os programas de Pós-Graduação, dentre os quais, a maior integração de autores a grupos de pesquisa, assim como a elaboração de trabalhos em conjunto por orientadores e orientandos. Com a intensificação da lógica de organização de grupos que oferecessem suporte às diferentes linhas dos programas de Pós-Graduação, as publicações coletivas passam a obter maior representatividade quantitativa no cenário acadêmico.

Quando analisamos o tipo de autoria dos artigos por conteúdo, conforme a Figura 2, observamos que, embora o Esporte apresente um volume maior de produção em relação às Lutas, em ambos os conteúdos, a procedência individual se sobrepõe à coletiva, ao 
contrário do que ocorre com as publicações sobre Dança, Ginástica, Jogos e Brincadeiras e Vários Conteúdos. Os estudos referentes à Capoeira foram produzidos de modo semelhante, tanto individual, como coletivamente.

Figura 2 - Procedência Autoral por Conteúdo

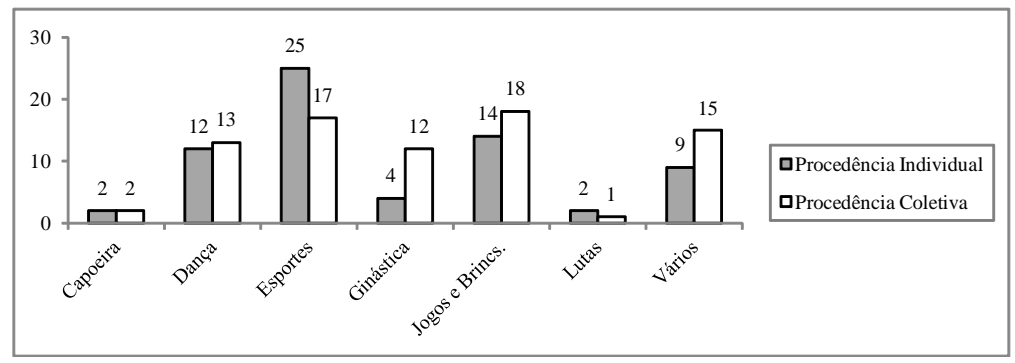

Fonte: Autores

Ao comparamos o tipo de autoria com a formação dos pesquisadores, percebemos que os trabalhos foram publicados por autores em diferentes níveis de titulação: graduandos (4), graduados (33), pós-graduando (1), especialistas (31), mestrandos (26), mestres (60), doutorandos (22), doutores (75), pós-doutorando (1), pósdoutores (10) e livre-docente (1). Relacionando os conteúdos de ensino com a formação profissional, verificamos uma concentração na produção de todos os conteúdos por parte de mestrandos, mestres, doutorandos e doutores.

Dos artigos produzidos individualmente (68), apenas 12 não foram publicados por pesquisadores com titulação stricto sensu e pós-doutorado, sendo distribuídos em Graduação (6), Graduação em andamento (1), Especialização (4) e Especialização em andamento (1). Destes, sete foram veiculados até o ano 2000. Dos trabalhos coletivos (78), encontramos apenas quatro escritos por especialistas (2) e graduados (2). Dois foram publicados até 2001. 
A aproximação entre a procedência autoral dos artigos, em sua distribuição anual, com a titulação dos pesquisadores, nos faz observar um movimento de qualificação profissional da área que ganha força no final da década de $1991^{6}$.

\subsection{DA RELAÇÃO ENTRE PROCEDÊNCIA TERRITORIAL E AUTORAL}

Dos estudos mapeados, 57 são procedentes da Região Sudeste (39\%), 50 do Sul (34\%), 11 do Centro-Oeste (8\%), 15 do Nordeste $(10 \%)$ e 1 do Norte (1\%). Foram encontrados ainda 11 trabalhos (8\%) de origem interestadual, internacional e entre instituições nacionais e internacionais ${ }^{7}$.

O lugar de referência que as Regiões Sudeste e Sul ocupam no campo científico é decorrente dos investimentos realizados em programas de pós-graduação, universidades e grupos de pesquisas (SANTOS, 2011; CARNEIRO, 2011). O Relatório de Reunião de Coordenadores de Programas de Pós-Graduação da Área 21 (BRASIL, 2011, p. 2), ao indicar a distribuição geográfica dos programas, evidencia a concentração de Programas de PósGraduação:

[...] A Região Sudeste contém aproximadamente 65\% (31 programas) dos programas da Área 21. Nota-se elevada concentração nos estados de SP, que responde por aproximadamente $45 \%$ dos cursos da Área 21. A Região Sul é a segunda maior região com cursos na Área 21, onde observam 23\% dos cursos aprovados.

Quando analisamos a procedência territorial das publicações e sua relação com os conteúdos, observamos a configuração presente na Tabela 4.

\footnotetext{
${ }^{6}$ Embora autores de diferentes níveis de formação publiquem desde 1986, é a partir de 1995 que notamos uma concentração de pesquisadores com maior formação, dos quais há mestrandos (26), mestres (58), doutorandos (19), doutores (75), pós-doutorando (1), pós-doutores (10) e livre-docente (1), correspondendo a 75\% de todas as assinaturas entre 1995 e 2010.

${ }^{7}$ Não foi possível a identificação da procedência territorial de 1 trabalho.
}

Movimento, Porto Alegre, v. 19, n. 02, p. 123-148, abr/jun de 2013. 
Tabela 4 - Procedência Territorial por Conteúdo

\begin{tabular}{l|c|c|c|c|c|c|c|c}
\hline \multirow{2}{*}{ Conteúdo } & \multicolumn{7}{|c|}{ R eg ião } \\
\cline { 2 - 10 } & $\begin{array}{c}\text { Cen tro- } \\
\text { Oes te }\end{array}$ & Nordes te & No rte & Su des te & Sul & Interes tadual & Int ernacion al & Nacion aV \\
\hline Capoeira & 1 & & & 1 & 2 & & & \\
\hline Dança & 2 & 5 & & 7 & 7 & 4 & & \\
\hline Es portes & 4 & 5 & 1 & 16 & 15 & 1 & & \\
\hline Gin ás tica & 1 & 1 & & 5 & 7 & & 1 & \\
\hline Jogos e Brincs. & 1 & 1 & & 18 & 10 & 1 & & 1 \\
\hline Lu tas & & 1 & & & 2 & & & \\
\hline Vários & 2 & 2 & & 10 & 7 & 3 & & \\
\hline Total & $\mathbf{1 1}$ & $\mathbf{1 5}$ & $\mathbf{1}$ & $\mathbf{5 7}$ & $\mathbf{5 0}$ & $\mathbf{9}$ & $\mathbf{1}$ & $\mathbf{1}$ \\
\hline
\end{tabular}

Fonte: Autores

As Regiões Sudeste e Sul fazem circular os conteúdos que possuem maior expressividade no campo acadêmico, com número significativo de artigos. De igual modo, publicam um grande volume sobre os demais conteúdos, demarcando assim, seus lugares de produção. Os trabalhos oriundos do Centro-Oeste e Nordeste apresentam-se com pouco impacto quantitativo, transitando por diferentes conteúdos, enquanto a Região Norte faz circular um estudo sobre Esporte. Na leitura dos resumos, observamos poucas discussões que nos remetessem à identidade cultural dessas regiões, o que poderia dar visibilidade à sua produção no cenário nacional.

Destacamos o volume de artigos produzidos por instituições de diferentes Estados (9), a partir de 1999. Autores oriundos do Sudeste têm publicado em parceria com o Sul (5), Centro-Oeste (1) e com o Nordeste (1). Há trabalhos que são originários de uma mesma região, como o Sudeste (1) e Nordeste (1). As aproximações estabelecidas entre os pesquisadores representam um meio para elevar a sua produtividade e fazer circular suas produções por diferentes espaços, sinalizando um perfil de interinstitucionalização dos estudos.

Foi possível mapearmos os pesquisadores que, ao se constituírem como referência numérica na área, significam seus discursos referentes aos conteúdos de ensino. Dos 215 autores presentes em toda a produção, selecionamos aqueles que ocupam lugar de permanência, ou seja, os que produziram, no mínimo, três trabalhos ${ }^{8}$.

${ }^{8}$ Tendo em vista o reduzido número de estudos por autor nas categorias Ginástica e Vários Conteúdos, consideramos os que possuem duas publicações. 
As autoras que mais têm pesquisado sobre Dança são Lívia Tenório Brasileiro, publicando artigos na Movimento (2002), Pensar a Prática (2003) e Motriz (2008), assim como Maria do Carmo Saraiva, com trabalhos na Motrivivência (1999), Movimento (2009) e RBCE (2009). Quanto ao Esporte, observamos as publicações de Suraya Cristina Darido na Motriz (2002, 2010, 2010), REF-UEM (2008, 2009) e Movimento (2008). Além disso, produziu um artigo sobre Vários Conteúdos publicado na Motriz (2005). A produção de Valter Bracht também possui expressividade quantitativa, com trabalhos veiculados na Movimento (1986, 2000) e RBCE (2003), sendo responsável pelo primeiro texto que tratou diretamente sobre esse conteúdo.

Dos artigos sobre Ginástica, Ieda Parra Barbosa-Rinaldi publica na REF-UEM (2007, 2010), Marco Antonio Coelho Bortoleto na Motriz (2003) e RBCE (2007), assim como Vilma Lení Nista-Piccolo, na Movimento (2007, 2008). Essa autora escreveu ainda sobre Jogos e Brincadeiras na RBCM (2004). Dentre os pesquisadores que abordam os Jogos e Brincadeiras, destacam-se Elaine Prodócimo, com estudos na RBCM (2004), Motriz (2006, 2007) e Pensar a Prática (2009), e João Batista Freire, com textos na Motriz (2007), Movimento (2008) e RBCE (2008). Paulo Rogério Barbosa do Nascimento abordou as Lutas em artigos publicados na Movimento (2007) e Motrivivência (2008).

Quanto aos trabalhos referentes a Vários Conteúdos, são evidenciados cinco autores. Ieda Parra Barbosa-Rinaldi e Larissa Michelle Lara publicaram na RBCE (2007) e em parceria com Amauri Aparecido Bássoli de Oliveira na Movimento (2009). O autor possui textos veiculados na REF-UEM $(1992,2002)$ e um artigo sobre Capoeira na REF-UEM (2001). Larissa Beraldo Kawashima fez sua produção circular na Motrivivência (2009) e na Motriz (2009), bem como Marcos Garcia Neira, que publicou na Motriz (2007) e Pensar a Prática (2008). Esse pesquisador ainda produziu um artigo sobre Dança na Motrivivência (2008) ${ }^{9}$.

${ }^{9} \mathrm{Como}$ as pesquisas referentes à Capoeira não possuem autores mencionados em mais de um artigo, não foi possível sua análise. 


\subsection{DA PROCEDÊNCIA INSTITUCIONAL AOS GRUPOS DE PESQUISA}

Ao organizarmos os trabalhos a partir da procedência institucional, verificamos a presença de 220 instituições ${ }^{10}$. Dentre elas, 62 são oriundas do ensino superior estadual (28\%), 66 do ensino superior federal (30\%), 48 do ensino superior privado (22\%), 2 do ensino superior estrangeiro (1\%) e 42 (19\%) da educação básica.

A autoria originária da educação básica concentra-se em 32 estudos, sendo 13 referentes à parceria entre orientandos e orientadores ${ }^{11}$, por meio de programas de Mestrado (3), Especialização lato sensu (6), Graduação (3) e Graduação/ Especialização (1). Dos artigos individuais (12), dois apresentam-se vinculados tanto a instituições de educação básica como a instituições de ensino superior.

Dos autores evidenciados como referência numérica, João Batista Freire orientou dois trabalhos vinculados ao Mestrado, bem como à Especialização. Larissa Michelle Lara e Ieda Parra Barbosa Rinaldi produziram dois artigos em parceria, como orientadoras da Graduação. Amauri Aparecido Bássoli de Oliveira orientou um estudo referente à Especialização. Dos que escrevem individualmente, Lívia Tenório Brasileiro publicou na Movimento, vinculada tanto à Secretaria de Estado da Educação de Pernambuco como à Universidade Estadual da Paraíba.

Notamos o volume expressivo de artigos assinados por autores de instituições de ensino superior particular em parceria com pesquisadores que já circulam na área, tendo em vista serem seus orientandos no Mestrado e Doutorado. Vilma Lení Nista-Piccolo produziu dois trabalhos como orientadora de alunos do Mestrado (2007, 2008) e um do Doutorado (2004). Suraya Cristina Darido

\footnotetext{
${ }^{10}$ Para a construção da tabela referente à Distribuição de conteúdos por instituição e posteriormente, da tabela de Relação de Grupos por conteúdos, assumimos como referência o mínimo de trabalhos.

${ }^{11}$ Dos 20 trabalhos assinados coletivamente, em sete artigos não foi possível a identificação da relação entre orientandos e orientadores, por meio da Plataforma Lattes ou informações explicitadas no corpo das pesquisas.
} 
publicou com orientando do Mestrado (2009) e em parceria com professor de pós-graduação stricto sensu e seu orientando (2010).

Essa relação é ampliada à medida que alguns desses autores participam dos grupos de estudos liderados pelos pesquisadores com maior produtividade, como é o caso de Neusa Dendena Kleinubing, orientanda de Maria do Carmo Saraiva no Mestrado e integrante do grupo liderado por ela. Assim como Claudio Kravchychyn, orientando no Doutorado e integrante do grupo coordenado por Amauri Bássoli de Oliveira.

Ao estabelecermos relação entre as Regiões, Estados e Instituições, conforme Tabela 5, observamos que alguns Estados têm se constituído como referência quantitativa. Embora já tenhamos verificado a representatividade numérica do Sudeste no fortalecimento da produção, percebemos que essa concentração é decorrente das publicações oriundas de São Paulo (49), com menor participação do Espírito Santo (3), Minas Gerais (4) e Rio de Janeiro (3).

Tabela 5 - Distribuição dos Conteúdos por Instituição

\begin{tabular}{|c|c|c|c|c|c|c|c|c|c|}
\hline R e giã o & Estado & In st ituição & C apoeira & D a n ça & Esport es & Gin ástica & $\begin{array}{l}\text { Jogos e } \\
\text { Brincs. }\end{array}$ & Vários & Total \\
\hline C entro-Oeste & GO & UFG & 1 & 1 & 3 & 1 & & & 6 \\
\hline Nordeste & PB & UEPB & & 3 & & & & & 3 \\
\hline Nordeste & $\mathrm{PE}$ & UFPE & & 1 & 3 & & 1 & 1 & 6 \\
\hline Sudeste & ES & UFES & & & 2 & & 1 & & 3 \\
\hline Sudeste & M G & UFM G & & & 2 & & 1 & 1 & 4 \\
\hline Sudeste & $\mathrm{RJ}$ & UERJ & & & 1 & & 2 & & 3 \\
\hline Sudeste & SP & M ET ROCAM P & & & 1 & 2 & & & 3 \\
\hline Sudeste & SP & REE - SP & & & 1 & & 2 & & 3 \\
\hline Sudeste & SP & U N E SP & & 2 & 6 & 1 & 1 & 4 & 14 \\
\hline Sudeste & SP & U N IC AM P & & 4 & 4 & 1 & 4 & 1 & 14 \\
\hline Sudeste & SP & U PM & & & & 1 & 1 & 1 & 3 \\
\hline Sudeste & SP & U S J T & & & & 2 & 1 & 1 & 4 \\
\hline Sudeste & SP & U SP & & 1 & & & 4 & 3 & 8 \\
\hline Sul & $\mathrm{PR}$ & UEL & & 1 & & 1 & & 1 & 3 \\
\hline Sul & $\mathrm{PR}$ & U EM & 2 & 1 & 3 & 3 & & 5 & 14 \\
\hline Sul & $\mathrm{PR}$ & UFPR & & & 2 & 1 & & & 3 \\
\hline Sul & RS & UFPel & & & 2 & 1 & & & 3 \\
\hline Sul & $\mathrm{RS}$ & UFRGS & & & 2 & & 1 & & 3 \\
\hline Sul & RS & UFSM & & & 2 & & & 1 & 3 \\
\hline Sul & SC & U D E SC & & & & & 3 & & 3 \\
\hline Sul & $\mathrm{SC}$ & U F SC & & 4 & 3 & 2 & 6 & 1 & 16 \\
\hline
\end{tabular}

Fonte: Autores 
Quando identificamos as instituições com maior expressividade quantitativa em São Paulo, observamos que a Unicamp (14) e a Unesp (14), representam $47 \%$ do que circulou naquela Região e $23 \%$ da produção evidenciada na tabela. Em contrapartida, na Região Sul, tanto o Paraná (20) como Santa Catarina (19) apresentam-se relevantes numericamente. A UEM (14) e a UFSC (16) são responsáveis por $63 \%$ das publicações na Região e por $25 \%$ da produção nacional ${ }^{12}$.

Essas demarcações podem ser consideradas como mecanismos empregados pelas instituições, a fim de que seus lugares de poder sejam evidenciados, reafirmando a "[...] regionalização da produção científica e sua concentração nos Estados em que há um fortalecimento dos programas de pós-graduação" (SANTOS, 2011, p. 158).

Dos 146 artigos mapeados, 126 estão vinculados à grupo de pesquisa. A análise da correlação entre a distribuição regional da produção com os grupos de pesquisa evidencia: 6 grupos no CentroOeste (5\%), 4 no Norte (3\%), 3 no Nordeste (2\%), 66 no Sudeste $(52 \%)$ e 47 no Sul $(37 \%)^{13}$.

Ao relacionarmos os grupos de estudos com a procedência institucional, observamos que $76 \%$ são provenientes das instituições que mais produzem na área, conforme Tabela 6.

Tabela 6 - Relação de grupos por conteúdo

\begin{tabular}{|c|c|c|c|c|c|c|c|c|}
\hline Região & Estado & Grupo de pesquisa & Dança & Esportes & Ginástica & \begin{tabular}{|c} 
Jogos \\
Brincs.
\end{tabular} & Vários & Total \\
\hline Suneste & $\Phi$ & ContextosIntegadosem Eduxação Infantil-USP & 1 & & & & 2 & 3 \\
\hline Suleste & $\Phi$ & Grupo de Estudbs e Pesquisa sobre Agressividade-UNICAMP & & & & 3 & & 3 \\
\hline Suneste & $\Phi$ & Grupo de Estudbs Avançadosem Int eligência Hmana USIT & & & 2 & 4 & & 6 \\
\hline Surleste & $\Phi$ & Grupo de Estudbs em Pedagggia do Esporte-UNICAMP & & 2 & 1 & & & 3 \\
\hline Suneste & $\Phi$ & Grupo de Pequisa em Ginástica-UNICAMP & & & 3 & & & 3 \\
\hline Sureste & $\Phi$ & Laboratório de Estudos solre Arte, Corpo e Edtração-UNICAMP & 3 & & & & & 3 \\
\hline Sundeste & $\Phi$ & Laboratório de Estudos e Trabalhos Pedag emEdıcação Físicat UNESP & & 5 & & & 2 & 7 \\
\hline Surleste & $\Phi$ & Núdeo de Estudbs e Pesquisaem Int eligência Corporal Cinestésica-UNICAMP & & & 2 & 3 & & 5 \\
\hline Sureste & $\Phi$ & Grupo de Pexquisa em Edıcação Física Escolar-UPY & 1 & & & & 2 & 3 \\
\hline Surleste & $\Phi$ & Grupo de Estub e Pesquisa Edrcação Físca e Cult ura-UNICAMP & & 2 & 1 & & & 3 \\
\hline Sul &  & Corpo, Giltura e Ludicidade-UEM & & & 2 & & 2 & 4 \\
\hline Sul & $\begin{array}{l}\mathrm{PR} \\
\end{array}$ & Grupo de Estudbs e Pesquissem Gnásica-UEM & & & 2 & & 1 & 3 \\
\hline Sul & $\overline{\mathrm{SC}}$ & Núdeo de Estudos Pedagógoos em Edıcação Físicat UFSC & 3 & & 1 & & & 4 \\
\hline
\end{tabular}

Fonte: Autores

\footnotetext{
${ }^{12}$ A UFSC constitui-se como a instituição que apresenta o maior número de artigos no cenário nacional.

${ }^{13}$ Os grupos foram mapeados a partir do ano de formação que consta no Diretório de Grupos de Pesquisa do CNPq. Não incluímos, dessa maneira, grupos formados posteriormente à produção do texto. Embora alguns não tenham sido localizados nesse Diretório, foram considerados na análise por se constituírem de informações dadas pelos próprios autores no corpo dos artigos.
} 
A leitura, pela via dos grupos de pesquisa, mostra-se interessante para entendermos como vêm se constituindo, no campo científico, os estudos sobre conteúdo de ensino. Para Bourdieu (1983, 1989), um campo científico se define como lugar de luta concorrencial pelo monopólio da autoridade científica. No caso dos artigos sobre conteúdos, observamos que o monopólio é compartilhado pelos pesquisadores que se configuram como membros de grupos de pesquisa, sobretudo, na figura de seus líderes.

A participação dos autores de maior recorrência, seja como pesquisadores dos grupos de estudos, seja como seus coordenadores, tem contribuído para a maior visibilidade de sua produção, como é o caso de Vilma Lení Nista-Piccolo e Elaine Prodócimo (líderes do Núcleo de Estudos e Pesquisa em Inteligência Corporal Cinestésica - Unicamp), Suraya Cristina Darido (líder do Laboratório de Estudos e Trabalhos Pedagógicos em Educação Física - Unesp) e Larissa Michelle Lara (líder do Corpo, Cultura e Ludicidade - UEM). Os dados evidenciam, mesmo indiciariamente, que a autoridade específica que está em jogo se apresenta como um estado da relação de força (GINZBURG, 2002) entre os grupos, as instituições e os pesquisadores que se configuram como referência quantitativa nos estudos sobre conteúdos de ensino.

A produção vinculada a grupos de pesquisa tem fortalecido as discussões referentes aos conteúdos de ensino, com o objetivo de estabelecer uma continuidade de publicações a partir de um dado referencial teórico, possibilitando uma leitura mais ampliada daquilo que se estuda, assim como evidenciando o projeto que norteia e oferece sustentação às suas publicações. Oferece ainda pistas para identificarmos os pesquisadores que se constituem como vozes autorizadas e com autoridade que possuem capacidade técnica e poder social para intervir e falar em nome de um determinado grupo.

\section{CoNSIDERAÇõES FINASS}

A partir da pesquisa em periódicos, é possível compreender as fontes como produtos de relações de força entre diferentes atores, 
autores e grupos de pesquisa e, assim, entender que são objetos culturais, por meio dos quais saberes, modelos e formas de pensar os conteúdos de ensino da Educação Física brasileira são colocados à leitura, indicando o modo como a área foi constituída historicamente.

Ao analisarmos as produções que tratam sobre conteúdos de ensino, damos visibilidade aos temas abordados de forma recorrente no campo acadêmico, àqueles que despontam como promissores e ainda aos que não são abordados. Embora as discussões relacionadas com o Esporte tenham assumido centralidade nos debates da área a partir de 1980, questionando-o como prática escolar e colocando em voga a legitimidade da Educação Física, observamos o impacto que esse conteúdo ainda obtém na produção. Para além da sua representatividade numérica, o panorama evidenciado nos leva a discutir a diversidade de práticas possível à Educação Física escolar, haja vista alguns trabalhos terem se dedicado ao trato pedagógico de diferentes possibilidades de intervenção.

Compreendemos, neste caso, que a especificidade de um componente curricular está no que se ensina e se aprende, ou seja, nos conteúdos. Ele nos oferece elementos para pensarmos a respeito de como tem se constituído as identidades da Educação Física no contexto escolar.

A aproximação da procedência territorial dos trabalhos da institucional nos revela que a localização das revistas é um indício para o fortalecimento da produção regional, uma vez que os textos oriundos dos Estados de maior expressividade quantitativa são veiculados de modo significativo em revistas patrocinadas por instituições localizadas em suas próprias regiões.

Em decorrência dessas relações, percebemos que muitos pesquisadores têm se constituído como referência numérica na área, pois sua produção se concentra nas revistas chanceladas pelas instituições de ensino superior em que estão vinculados, ou em periódicos localizados em sua região. Observamos ainda que esta produção, em grande parte, está relacionada aos Programas de PósGraduação, suas linhas de estudo e aos grupos de pesquisa que oferecem suporte teórico-metodológico. 


\section{Artigos Orignais}

A presença de um elevado número de autores (215), instituições (220) e grupos (126), ao longo das três décadas estudadas, tem sinalizado para a consolidação do debate sobre conteúdo de ensino. Além disso, essa produção tem se fortalecido e se qualificado à medida que os pesquisadores publicam periodicamente e em diferentes momentos de sua formação, demonstrando a relevância que o tema tem assumido no cenário acadêmico.

Diante do panorama apresentado, sinalizamos para a necessidade de estudos que discutam o conteúdo dos textos e as práticas de apropriação relacionadas com as matrizes teóricas que os fundamentam, evidenciando as implicações que esses discursos trazem às singularidades da Educação Física como componente curricular. 
The academic production on teaching contents in Physical Education

Abstract: It aims to analyze the academic productions on teaching content of Physical Education. Uses as a source, the scientific journals in the area from 1981 to 2010. We mapped 146 articles in 14 journals. The data were classified and analyzed by bibliometric indicators, such as annual distribution, magazine distribution and content, copyright relation, professional training, demographic and institutional origin, as well as their link to research groups. While there is, in the academic production, a discourse that questions the sports as the main practice of Physical Education, it continues as the focus of the most papers.

Keywords: Physical education. Scientific production. Teaching contents. Journal.

\begin{tabular}{l} 
La producción academica sobre contenidos de \\
ensanãnza en la Educación \\
Fisica Escolar \\
Resumen: Objetiva analizar las producciones \\
académicas que tratan sobre los contenidos de \\
enseñanza de la Educación Física escolar. Utiliza como \\
fuente los periódicos científicos del área en el período \\
de 1981 hasta 2010 . Fueron mapeados 146 artículos \\
distribuidos en 14 periódicos. Los datos fueron \\
clasificados / analizados por medio de indicadores \\
bibliométricos, como distribución anual, distribución por \\
revistas y por contenidos, relación autoral,formación \\
profesional, origen demográfica y institucional, así \\
como vínculo a grupos de pesquisa. Aunque haya, en \\
la producción académica, un discurso que cuestione \\
el Deporte como práctica central de la Educación Física \\
escolar, este continúa concentrando mayor volumen \\
de trabajos. \\
Palabras-clave: Educación física. Producción \\
científica. Contenidos de enseñanza. Periódico. \\
\hline
\end{tabular}




\section{REFERÊNCIAS}

ANDRÉ, M. A produção acadêmica sobre formação de professores: um estudo comparativo das dissertações e teses defendidas nos anos 1990 e 2000. Formação Docente: Revista Brasileira de Pesquisa sobre Formação Docente, v. 1, n. 1, p. 41-56, ago./dez. 2009.

BOURDIEU, P. Sociologia. Rio de Janeiro: Ática, 1983.

BOURDIEU, P. O poder simbólico. Rio de Janeiro: Ática, 1989.

BRACHT, V. et al. A Educação Física Escolar como tema da produção do conhecimento nos periódicos da área no Brasil (1980-2010): parte I. Movimento, Porto Alegre, v. 17, n. 2, p. 11-34, abr./jun. 2011.

A Educação Física Escolar como tema da produção do conhecimento nos periódicos da área no Brasil (1980-2010): parte II. Movimento, Porto Alegre, v. 18, n. 2, p. 11-37, abr./jun. 2012.

BRASIL. Ministério da Educação. Relatório da Reunião de Coordenadores de Pós-Graduação da Área de Educação Física, Fisioterapia, Fonoaudiologia e Terapia Ocupacional: Ofício no 028, de 23 de outubro de 2011. Curitiba, 23 out. 2011.

CARNEIRO, F. F. B. Políticas científicas em educação física: a arqueologia do GTT Escola no Congresso Brasileiro de Ciências do Esporte (1997-2009). 2011. Dissertação (Mestrado em Educação Física) - Programa de Pós-Graduação em Educação Física, Universidade Federal do Espírito Santo, Vitória, 2011.

CATANI, D. B.; SOUSA, C. P. de. O catálogo da imprensa periódica educacional paulista (1890-1996): um instrumento de pesquisa. In: . (Org.). Imprensa periódica educacional paulista (1890-1996): catálogo. São Paulo: Plêiade, 1999. p. 9-30.

CERTEAU, M. de. A invenção do cotidiano: 1. artes de fazer. 15. ed. Petrópolis: Vozes, 2002.

CHARLOT, B. Da relação com o saber: elementos para uma teoria. Porto Alegre: Artmed, 2000.

CHARLOT, B. Ensinar a educação física ou ajudar o aluno a aprender o seu corposujeito? In: DANTAS JÚNIOR, H. S.; KUHN, R.; RIBEIRO, S. D. D. Educação física, esporte e sociedade: temas emergentes. São Cristóvão: Editora da UFS, 2009. v. 3 , p. $231-246$. 
DARNTON, R. Introdução. In: DARNTON, R.; ROCHE, D. (Org.). Revolução impressa: a imprensa na França-1775-1800. São Paulo: Edusp, 1996. p. 15-17.

DAVIS, N. Z. O retorno de Martin Guerre. Rio de Janeiro: Paz e Terra, 1990.

FALCÃO, J. L. C.; SILVA, B. E. S. da; ACORDI, L. de O. Capoeira e os passos da vida. In: SILVA, A. M.; DAMIANI, I. R. (Org.). Práticas corporais: experiências em educação física para a outra formação humana. Florianópolis: Nauemblu Ciência \& Arte, 2005. p. 17-45.

FERREIRA NETO, A. et al. Catálogo de periódicos de educação física e esportes (1930- 2000). Vitória: Proteoria, 2002.

Fórmula editorial e graduação: 15 anos de Motrivivência. Motrivivência, Florianópolis, ano 15, n. 20-21, p. 57-90 mar./dez. 2003.

GINZBURG, C. Relações de força: história, retórica, prova. São Paulo: Companhia das Letras, 2002.

FUNARO, V. M. B. de O.; NORONHA, D. P. Literatura cinzenta: canais de distribuição e incidência das bases de dados. In: POBLACIÓN, D. A.; WITTER, G. P.; SILVA, J. F. M. da. (Org.). Comunicação e produção científica: contexto, indicadores, avaliação. São Paulo: Angellara, 2006.

HUNT, L. A nova história cultural. São Paulo: Martins Fontes, 1995.

MOROSINI, M. C. et al. A produção científica sobre educação superior no Brasil: 1968-2000. Porto Alegre: GT Política de Educação Superior/Anped, 2002. Disponível em: <http://www.pucrs.br/faced/pos/universitas/>. Acesso em: 5 jun. 2012.

MUGNAINI, R.; CARVALHO, T. de; CAMPANATTI-OSTIZ, H. Indicadores de produção científica: uma discussão conceitual. In: POBLACIÓN, D. A.; WITTER, G. P.; SILVA, J. F. M. da (Org.). Comunicação e produção científica: contexto, indicadores, avaliação. São Paulo: Angellara, 2006.

SANTOS, W. dos. A constituição do campo pedagógico do currículo: estratégias, apropriações e circularidades culturais. 2011. Tese (Doutorado em Educação) - Programa de Pós-Graduação em Educação, Universidade Federal do Espírito Santo, Vitória, 2011.

SCHNEIDER, O. et al. Arqueologia das práticas editoriais: 15 anos de um impresso em Movimento. Movimento, Porto Alegre, v. 15, n. 3, p. 57-85, jul./set. 2009.

SCHNEIDER, O. Educação physica: a arqueologia de um impresso. Vitória: Editora da Ufes, 2010. 


\section{ArtigosOriginais}

SCHNEIDER, O.; BUENO, J. G. S. A relação com os saberes compartilhados nas aulas de educação física. Movimento, Porto Alegre, v. 11, n. 1, p. 23-46, jan./abr. 2005.

SOUZA, J. de; MARCHI JÚNIOR, W. Por uma sociologia da produção científica no campo acadêmico da Educação Física no Brasil. Motriz, Rio Claro, v. 17, n.2, p. 349-360, abr./jun. 2011. Disponível em: < http://www.periodicos.rc.biblioteca. unesp.br/index.php/motriz/article/view/1980-6574.2011v17n2p349>. Acesso em: 15 fev. 20.

Endereço para correspondência:

Juliana Martins Cassani Matos

PROTEORIA

Caixa Postal 9905

AGF UNIVERSITÁRIA

Rua Arthur Czartoryski 455 Loja 1

CEP.: 29060-974

Recebido em: 17.10.2012

Aprovado em: 10.12.2012

Movimento, Porto Alegre, v. 19, n. 02, p. 123-148, abr/jun de 2013. 